\title{
La comprensión por el niño de la intención del mensaje publicitario
}

\section{Pedro Vida*}

\author{
Universidad Complutense
}

\section{INTRODUCCION}

La intención fundamental de este artículo es centrar la atención del lector en un complejo proceso que media, habitualmente, las relaciones entre el consumidor y el producto. La Publicidad, como forma típica de comunicación entre productores y consumidores, supone una vicarización de la original relación directa entre los actores del consumo, y acarrea un conjunto de dificultades añadidas por la necesidad de comprensión, en los distintos públicos, del contenido e intención de sus mensajes. Ello presenta perfiles singulares en lo concerniente a un público receptor concreto como son los niños, cuya alfabetidad (literacy) general y publicitaria aún no es completa, con lo que los efectos pretendidos por el emisor se ven sometidos a un conjunto de modificaciones directamente relacionadas con este hecho.

Se propone en este artículo un modelo de comprensión para este tipo específico de discurso, dando especial relevancia a un cierto nivel estructural en el que se soporta gran parte del proceso de comprensión, obteniéndose algunas consecuencias de diversa índole en lo relativo a la relación anuncio-niño en el seno de una especulación teórica de enmarcamiento múltiple.

\section{LA PUBLICIDAD Y EL NIÑO}

Uno de los elementos facilitadores del consumo es la comunicación relativa a los bienes y servicios, y dentro de ella es ya un lugar común el que la publicidad ocupa una posición privilegiada, pudiendo ella misma ser objeto de consumo e incluso vehículo único de generación y sostenimiento de los productos (vid. González y Benavides en este número).

En este sentido, y sin ánimo de profundizar en el modo de funcionamiento de la Publicidad como. sistema en el seno de otros sistemas (consumo, sociedad, etc.), sí conviene preguntarse por el papel concreto de la misma en el proceso global del consumo y para ello, un primer paso es conocer cómo se recibe y comprende por parte de los distintos públicos afectados. Entre ellos los niños, como neófitos en la competencia social y comunicativa, cuyo desarrollo les permitirá posteriormente desenvolverse con soltura en su medio (vid. Hernández en este número), son un público especialmente interesante para la comprensión de este tipo de comunicación, y no sólo eso, sino también como objeto potencial de especulación teórica en el dominio de la comprensión textual más amplia.

\footnotetext{
* Dirección del autor: Universidad Complutense, Facultad de Ciencias de la Información, Avda. Complutense
} $\mathrm{s} / \mathrm{n}, 28040$ Madrid. 
Al igual que otras formas de comunicación, la Publicidad se manifiesta en forma de mensajes materiales difundidos a través de los distintos medios de comunicación. Su pretensión es lograr la influencia necesaria en los receptores para que se manifieste en forma de adhesión de estos a las propuestas que contiene, siendo fundamentalmente una incitación al consumo de productos y servicios de la mas diversa índole.

La comprensión de la Publicidad requiere pues un conjunto de conocimientos y habilidades en el receptor de forma que pueda captar la intención del acto-de-habla-publicitario como paso previo al logro del efecto deseado por el emisor.

Lo que aquí nos interesa es cómo la Publicidad puede lograr esto en sujetos cuya alfabetidad aún es incompleta, entendida ésta desde el punto de vista de la cantidad de conocimientos disponibles y destrezas o habilidades necesarias para desentrañar los significados, sentidos y referencias del discurso publicitario.

Lo que se constata es que independientemente del modelo de niño que se maneje, éste es sensible desde muy temprana edad a los mensajes publicitarios, fundamentalmente a los televisivos, y ello contrasta con la supuesta complejidad de tal forma de comunicación, con lo que parece preciso revisar algunos de los planteamientos anteriores de la investigación de este fenómeno.

\section{LA PUBLICIDAD EN EL NIÑO}

Si la Publicidad es, desde sus primeros mèsés, atractivā pārā el niño es porque, frente a lo que pudiera pensarse, es bastante primigenia en la construcción de sus actos-de-babla componentes, estando más próxima en cuanto a interpretación, al menos de algunas de sus partes, a la comprensión del niño (por los formatos que utiliza) que otras formas de interacción comunicativa textual más sofisticadas y que implican una mayor simbolización o etiquetación, así como una mayor abstracción de sus referencias.

En el párrafo precedente se ha mencionado, en forma sumaria, la propuesta fundamental de este artículo y es preciso revisar con algún detalle los distintos elementos que contiene.

Siempre que se ha tratado de los usos que hacen los sujetos de la comunicación, ha sido preciso partir de algún modelo de mensaje que soporte dicha comunicación y de algún modelo de sujeto que opere de alguna forma sobre dicho mensaje. Hasta ahora tales modelos no eran lo suficientemente explícitos y adecuados como para poder dar cuenta de las relaciones completas entre ambos. Así, desde la lingüística, hasta hace poco tiempo, lo único susceptible de investigación eran las frases o sentencias, como unidades terminales máximas que consideraban esta disciplina, en suma el nivel superficial del lenguaje. No ha sido hasta la aparición de la Lingüística del Texto cuando se ha podido operar con unidades mayores a la frase que, siendo unidades comunicativas completas, se han considerado propiamente lingüísticas (Schmidt, 1973; van Dijk, 1977). Lo fundamental de dichas unidades textuales no es sin embargo su organización estructural interna, que también es objeto de profunda investigación, sino el hecho de funcionar como formatos globales de interacción social (Halliday, 1978), siendo a su vez una componenda de formatos más elementales aglutinados por alguna estructura interna del discurso. Es así también como, bajo esta concepción, se capacita la inserción en el discurso de múltiples formas de codificación que hagan efectivo el acto comunicativo (van Dijk, 1978), transcendiendo la codificación verbal como única hasta ahora accesible a la Lingüística.

En este sentido, nuestra consideración del mensaje publicitario será como texto, y más propiamente como acto-de-habla-global, con una es- 
tructura jerárquica de actos-de-habla componentes que, aunque autonomizables, funcionan adecuadamente en el interior de distintas configuraciones que atienden a una meta funcional única.

Otro tanto ha ocurrido con el sujeto productor y receptor de los mensajes, que de ser una instancia cuya única misión consistía en conectar ciertos estímulos, simples o complejos, a una jerarquía de respuestas, ha pasado a ser un sistema que basa su conducta en el conocimiento, y más propiamente en la naturaleza, organización y contenido del mismo, que determina su conducta intencional.

Partimos así de dos precondiciones necesarias, como son el considerar a los mensajes publicitarios como actos-de-habla, y a los sujetos como sistemas de procesamiento de información que seleccionan, representan y utilizan dicha información en sus interacciones.

\section{UN MODELO FUNCIONAL DEL MENSAJE PUBLICITARIO}

Casi todas las respuestas actuales de la Lingüística del Texto coinciden en delimitar al menos dos dominios de descripción y organización para el discurso (Bernárdez, 1982): a) un nivel global, que se obtiene como proyección de b) un nivel local, de manifestación material real del texto (van Dijk, 1977, 1978). Ambos niveles en sus dimensiones tanto sintácticas como semánticas y pragmáticas.

Una noción capital en este sentido fue la de macroestructura semántica (van Dijk, 1980), que trataba de dar cuenta de los significados, sentidos y referencias globales de los textos, pero incapaz de responder a ciertas nociones de genericidad de los discursos, siendo necesario un constructo teórico más, que permitiese soportar esta noción de género, a todas luces necesaria para una correcta interpretación de los discursos globales.

La noción que se implicaba es que, además de su macroestructura, que soporta el tema o tópico global, los textos disponen de alguna otra estructura que permite distinguir el género de un texto de todos aquellos otros que, pudiendo tener el mismo tema, muestran un funcionamiento interactivo o social diferente. Asi aún refiriéndose a lo mismo, un robo por ejemplo, será distinto un informe policial del mismo, que un artículo periodístico sobre dicho tema, o una novela que trate del asunto.

Con algunos precedentes provenientes de la teoría de la Literatura (Hernadi, 1978) y alguna investigación relativa a la memoria para relatos (Rumelhart, 1975), van Dijk propone la noción de superestructura esquemática de texto (van Dijk, 1978) para dar respuesta a esa necesidad teórica.

La superestructura es, entonces, lo que podemos considerar como el componente sintántico global del texto (García Berrio, 1983), que organiza jerárquicamente la macroestructura semántica del mismo.

Es así como todos los discursos, entendiendo por tales la virtualidad comunicativa que se manifiesta en un tipo de texto, deben tener una superestructura esquemática, que es lo que permite propiamente hablar de tipos de discurso diferentes.

El papel de estas estructuras en la comprensión de los discursos parece capital, así como lo demuestran las investigaciones sobre comprensión y recuerdo para cuentos (Marchesi y Paniagua, 1983) y para otros tipos de texto (Randquist, 1985).

La noción, por otra pare, está muy próxima a la de esquema, en el dominio de la psicología cognitiva (Rumelhart y Ortony, 1977), con lo que sus usos cognitivos parecen ser los mismos: representación cognitiva de algín tipo de objeto, conducta o situación (en este caso la superestructura esquemática, es el esquema de un tipo de texto, como estereotipo, o formato canónico de una categoría), siendo así su utilización cognitiva la misma, tanto para la producción como para la comprensión (derivaciones que se obtendrán más adelante). 
¿Cuál es entonces el esquema, superestructura esquemática u organización canónica del discurso publicitario?

Según lo concibo, y frente a otras interpretaciones ${ }^{1}$, los mensajes publicitarios son, eminentemente, un tipo de texto argumentativo, que trata de justificar o de dar buenas razones que convenzan al receptor sobre algún tipo de conducta a que le incita (sea ésta cognitiva o factual). Este será pues el acto-de-habla fundamental que debe soportar su superestructura esquemática, pero la argumentación es en relación a algo que debe ser referido en el discurso, con lo que habrá también una categoría de presentación del objeto del discurso. Pero para que ambas puedan operar se precisa una tercera categoría que reclame la intención del receptor de nuestro mensaje, y una cuarta que le proponga alguna conclusión del proceso de argumentación.

Es así como nuestro texto, o acto-de-habla-global publicitario se organiza canónicamente conforme al siguiente esquema o superestructura esquemática:

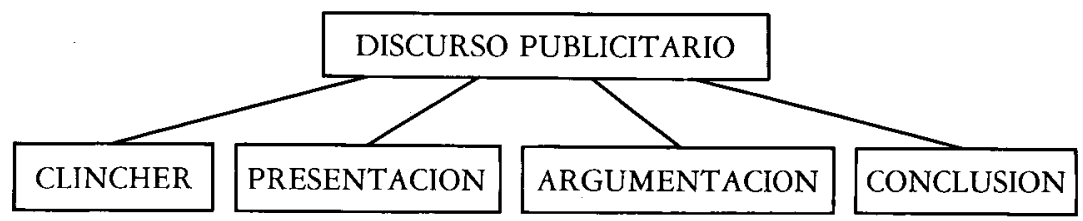

FigURA 1

Categorias del acto-de-babla publicitario

Cada una de estas categorías es a su vez un acto-de-habla en sí mismo que se atiene a un formato particular, o estructura esquemática, que lo organiza en sus constituyentes funcionales.

Desarrollando pues, con algún detalle, nuestra superestructura esquemática particular, el acto-de-habla publicitario se organiza como muestra la figura 2.

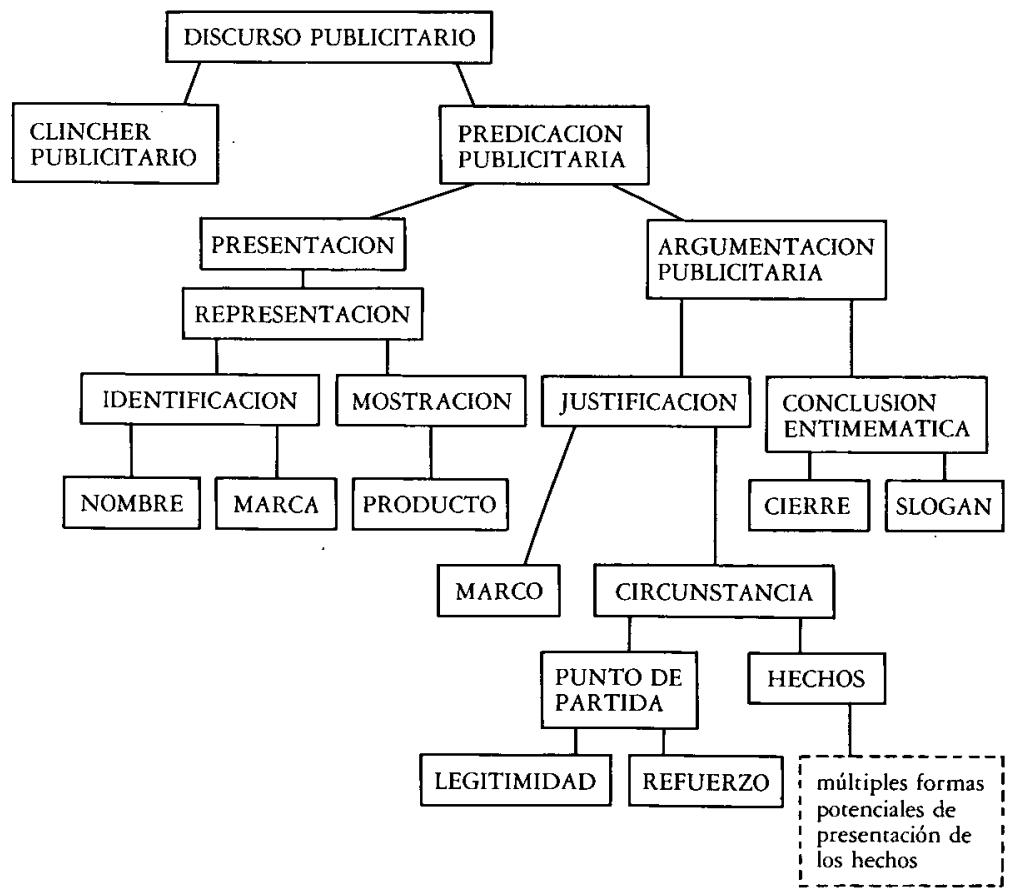

Figura 2 
El clincher, o categoría de llamada atencional, es autonomizable y cuenta en publicidad con elementos terminales especializados, como el titular o ciertas formas de imagen, aunque frecuentemente se superpone a alguna otra categoría.

Bajo la categoria de presentación publicitaria se hallan tanto la presentación del producto cuanto la argumentación publicitaria y como categoría de argumentación la conclusión del discurso, también especializada en publicidad en la frase cierre y el slogan.

Toda presentación requiere de una representación semiótica, que puede alcanzar sofisticadas cotas de simbolización, cumpliendo en publicidad dos funciones, como son identificar el producto y mostrarlo de alguna manera (Peninou, 1972).

La argumentación se ejecuta a fin de justificar alguna característica atribuible al producto, que aporta alguna razón para su adquisición, o la adhesión del receptor. Se trata de justificar alguna circunstancia soportada por unos hechos concretos, que suele ser el punto de vista particular del emisor respecto al producto. Ello dentro de un marco donde tal propuesta adquiere validez, el punto de partida es la apelación a algún principio, norma, ley o consenso que aporta la legitimidad de la proposición, aparte de alguna evidencia que refuerce tal opción.

La categoría de exposición de los hechos es la más problemática, pues implica una posibilidad múltiple de enfoque desde distintas posiciones, que será la base de argumentación en las tres vías clásicas de la retórica, ethos, pathos y logos (Carrera, 1978, 1980, Connor y Laver, 1985, Kopperschmidt, 1985), que exige para su comprensión una cierta capacidad de descentración del receptor a fin de captar el punto de vista del emisor y su propio papel como destinatario del mensaje.

Los hechos pueden ser insertados en el discurso de muchas formas posibles (Kopperschmidt, 1985), donde una de las posibilidades es la narración o relato que, en ocasiones ante la elisión de otras categorías, puede conferir al discurso publicitario aspecto narrativo, utilizando para ello (para su desarrollo) el esquema de la narración en cualquiera de sus variantes actuales (Rummelhart, 1975, Thorndyke, 1977). Pero al igual que mediante relato, los hechos pueden presentarse en un nuevo ciclo argumentativo, informe técnico o mediante simple descripción o exposición.

La brevedad del artículo no permite una exposición más detallada de las categorías, organización y funciones de la superestructura esquemática del texto publicitario, pero lo expuesto es suficiente a los fines pretendidos (para un mayor abundamiento ver Vidal, 1986).

Lo importante de tal estructura aquí no es tanto lo que implica de preceptivo en la producción de los mensajes, cuanto la funcionalidad del constructo a fines comprensivos. Cada categoría de alto nivel (clincher, presentación, argumentación y conclusión) funciona como un acto-de-habla con su propia estructura. Acto-de-habla que, aunque autonomizable, adquiere nueva función en el seno de la configuración, proporcionando condiciones de felicidad, en el sentido searleano del término (Searle 1965, 1969), para el acto-de-habla principal o argumentación, puesto que establecen las precondiciones necesarias para que esta pueda ser ejecutada, ello es coherente con el planteamiento de la tripartición del acto-de-habla en preparatorio-principal-conclusivo. Pero es sabido que una vez convencionalizado el formato de ejecución del acto-de-habla y en un contexto con limitaciones del grado de libertad, basta el acto-de-habla preparatorio para mostrar la intención del emisor, haciendo innecesario el principal. Ello ocurre así mismo en publicidad, donde, mediante intertextualidad, tan sólo la 
presentación es necesaria en ocasiones, dejando libertad al emisor de adscribir el ciclo argumentativo-valorativo tradicional a este tipo de discurso, y una aparente libertad en la obtención de las conclusiones.

En otras ocasiones sólo éstas aparecen en el mensaje en forma de slogan unido a la marca.

Vemos ya, en estas breves notas, el funcionamiento como esquema de tal constructo, principalmente al permitir asignaciones para categorías ausentes (Rumelhart y Ortony, 1977), pero para ello es preciso un conocimiento previo del esquema, al menos en sus atributos de alto nivel (categorías principales de la superestructura), o actos-de-habla componentes.

Nuestra propuesta queda clara entonces: para comprender el acto-debabla publicitario es preciso conocer los actos-de-babla componentes y su organización en la superestructura esquemática del mensaje publicitario, de manera que un desconocimiento de los componentes impide la comprensión plena, y un desconocimiento de la articulación de los mismos permite tan sólo una comprensión parcial inarticulada de cara a comprender el fin o meta global del acto.

Indudablemente faltaría completar el panorama mediante un recurso a los principios cooperativos de Grice para una completa comprensión de los actos-de-habla (Grice, 1975), pero tal descripción excede los límites de este artículo.

\section{LA INTERACCION COMUNICATIVA EN EL NIÑO}

Lo interesante aquí, a partir de ahora, es tratar de determinar en qué medida el niño está capacitado para la comprensión de los mensajes publicitarios y hasta dónde es capaz de comprender en cada etapa de su desarrollo.

Indudablemente no se pretende un análisis exhaustivo del proceso de comprensión que atienda a los distintos niveles de procesamiento, en línea con los sofisticados modelos actuales, tanto en psicología cognitiva (Kintsch, 1977; van Dijk y Kintsch, 1983) como en inteligencia artificial (Schank y Abelson, 1977; Schank, 1982), porque además nuestra perspectiva no incide de lleno en los aspectos sintáctico y semántico del mensaje, más que como niveles supeditados al dominio pragmático de los usos del lenguaje. Además, nosotros comenzamos en el punto donde concluyen los modelos de comprensión más clásicos.

Parto de la suposición de que el niño aprende a comunicarse antes que a hablar, y que cuenta para ello con una cierta predeterminación innata. Que aprende antes la estructura y funcionamiento de los actos comunicativos que su actualización sintáctico-semántica, como actos-de-habla, en cualquiera de los idiomas o lenguajes naturales. En este sentido me adhiero al planteamiento teórico de Bruner, cuando establece las bases para la adquisición de los actos-de-habla por el niño (Bruner, 1981, 1983, 1984).

En este autor la noción fundamental es la de intencionalidad de la conducta, intencionalidad de la acción infantil que es ejecutable, en función de las capacidades, por virtud del plan de acción en un contexto. El plan es lo aprendible, es la estructura superficial de la intencionalidad de acción e interacción, dándose entre interacción y plan una relación de profundo-superficial, con lo que el plan es susceptible de aprendizaje si se limitan adecuada y controladamente los grados de libertad en un contexto iterativo (e interactivo). 
Para dar respuesta a este concepto propone la noción de formato, que define como «una pauta de interacción estandarizada e inicialmente microcósmica, entre un adulto y un infante, que contiene roles demarcados que finalmente se convierten en reversibles» (Bruner, 1983).

A través de los formatos, el niño puede articular su interacción con el mundo, dotándola de una cierța sistematicidad que le permitirá un control creciente por expectativa de los resultados de la interacción.

Los formatos existen inicialmente para intenciones individualizadas, aunque con el tiempo, y una sistematicidad creciente, se van agrupando en subrutinas de un orden más elevado, con módulos a partir de los cuales se construyen una interacción social y un discurso más complejos.

Así, podemos considerar a los formatos como proto-actos-de-habla que devienen, por virtud de las etiquetaciones, en actos-de-habla en el sentido austiniano del término (Austin, 1962), pudiendo ser impuestos por mecanismos ilocutivos diversos en una gran variedad de situaciones.

El niño va aprendiendo a través de los formatos cosas tales como reclamar la atención, referir, pedir, rechazar, valorar, etc., inicialmente por medios no lingüísticos y posteriormente, a medida que adquiere las etiquetas y la simbolización del acto, por procedimientos verbales.

Es así como la activación del formato no se limita a un conjunto de etiquetas superficiales del lenguaje, sino que adquiere un repertorio de posibilidades equifuncionales que preservan la intención comunicativo-interactiva, perspectiva ésta ya contemplada en la Tagmémica de Pike (Pike, 1967).

En la medida en que cualquier mensaje respete la estructura de un formato, o formatos, utilizando para su actualización el repertorio de etiquetas o convenciones conocidas, en cada etapa evolutiva, por el niño, éste será capaz de comprender en cierta medida dicho mensaje, e incluso con cualesquiera otras etiquetas si éstas son iconos o índices, menos arbitrarios que los símbolos (Pierce 1932-1934, González Martín, 1982).

Es posible, entonces, una comprensión individualizada de ciertos formatos componentes de un mensaje, aunque pueda no comprenderse el texto en su globalidad, para lo que sería preciso disponer del formato o esquema de orden superior, que hemos denominado superestructura esquemática, como macro-acto-de-habla con una intención global. Esto explicaría la comprensión y recuerdo parcial de los anuncios televisivos, por parte de los niños, obtenidos por algunas investigaciones, aunque en otra orientación, como la piegetiana seguida por Ward y Wackman, 1973. Estos autores constatan el hecho, pero lo explican a tenor de un supuesto sincretismo y yuxtaposición que, en última instancia, deja inexplicado el fenómeno.

\section{LA COMPRENSION DE LA PUBLICIDAD POR EL NIÑO}

Según lo expuesto, y en función de la superestructura esquemática establecida, el niño para comprender un mensaje publicitario, además de su contenido referencial, que posteriormente veremos, debería comprender, en alguna forma las categorías fundamentales de dicha estructura, entendiéndolas como partes funcionales de un acto único de algún agente para la obtención de alguna meta pragmática. Esta comprensión plena es, sin embargo, muy tardía y su aprendizaje se produce de manera paulatina. No obstante desde muy temprana edad el niño está en disposición de com- 
con el niño, es la mostración el procedimiento principal. Igual hace la publicidad, que refiere casi siempre por mostración. Incluso usando la estrategia de aparición súbita, tan frecuente en los juegos infantiles (el cu-cutras entre otros). Así, el objeto publicitario muchas veces se demora en su aparición, y todo el acto-de-habla publicitario es una preparación para la aparición del mismo (sobresignificado casi siempre), incluso de forma burda o primigenia, haciendo aparecer el objeto de detrás de algo, o levantando algo que lo cubre.

Esta forma de referencia es conocida para el niño. Es más bien al adulto a quien sorprende, pues espera formas más sofisticadas de referir, con lo que estos procedimientos primarios le resultan sorpresivos, cumpliendo así una función fáctica añadida cara al adulto.

Para el niño, sin embargo, ahí está la fuerza de la publicidad en televisión desde sus primeros años. La referencia se establece visualmente, mediante focalización a la que ayudan las tecnologías (primeros planos, angulares, descripción visual en detalle, etc.), y luego un mecanismo predicativo-visual, como en el caso de la publicidad de juguetes, que le permite comprender que dicha conducta se refiere al objeto, como en sus formatos familiares, conducta de manipulación o de mimesis de conductas adultas que son deseables por el niño.

La publicidad en este caso sigue una doble vía:

a) la predicativo-verbal, con todas las convenciones valorativas que inician la argumentación, y

b) la predicativo-visual que, con el uso de las tecnologías, permite una sobresignificación objetual (Beaudrillard, 1984) que acarrea una mayor deseabilidad del objeto, que ya es suficiente argumento (predicación) para el niño.

Desde este abordamiento pragmático a la interacción, tanto en la orientación de la teoría de los actos-de-habla, como en otras, lo dominante pues es la intención, y las condiciones de ejecución que determinan el formato interactivo.

El aprendizaje de tales formatos es posible porque siempre responden a la misma intención interactiva. Así, partiendo del formato es posible derivar la intención que subyace y viceversa. Es decir, partiendo de la intención se asigna el formato óptimo, o simplemente conocido, de ejecución conductual para el logro de la meta interactiva que pretende alcanzar una situación deseada.

Es así como es posible aprender, en la interpretación de Bruner, los formatos de ejecución de los actos-de-habla, manteniendo la meta y asignándole formato.

En el aprendizaje adulto es así, también, como funciona, de ahí que una serie de tareas sean aprendidas como rutinas respondientes a una intención, una vez ha sido descubierta la pauta de ejecución. Por ejemplo, es posible aprender un oficio porque se conoce cuál es la meta de la tarea, y por tanto se limitan a una sola alternativa funcional todas las conductas resolutivo-ejecutivas del sujeto modelo, eliminando otras posibles interpretaciones. Con lo que al relacionarse ambas, intención y formato ejecutivo, de cualquiera de ellas es posible derivar la otra. Los problemas surgen, no tanto de una indefinición de las conductas, cuanto de una indefinición de las metas pragmáticas, esto es, el no saber a dónde queremos llegar con una conducta concreta, que es susceptible de múltiples interpretaciones teleológicas o intencionales. Es también el problema principal 
para el niño respecto a la publicidad en sus primeros años. Al desconocer al agente emisor es incapaz de derivar la intención del discurso publicitario del propio anuncio. Para ello necesitaría un formato de transacción, donde el emisor pudiese ser ubicado como agente de la misma, para la cual la publicidad es un recurso.

La comprensión del niño, pues, durante los primeros años se limita a comprender los formatos de referencia y predicación, donde la argumentación tiene un papel principal de cara a convencer al receptor de lo beneficioso de una conducta (adquisitiva casi siempre).

El formato de la argumentación también es comprensible para el niño desde una edad temprana. Entendemos la argumentación como el «conjunto de técnicas discursivas tendentes a provocar o incrementar la adhesión de un receptor a las tesis presentadas» por un emisor (Perelman, 1970). Es, en el fondo, una estrategia de adecuación cognitiva; se trata de un modelo de mundo construido por el locutor a la vista del modelo supuesto del interlocutor y del modelo al cual este interlocutor debe llegar, en términos accionales la argumentación es un cambio de estado: del no conocimiento al conocimiento, de la no acción a la acción (Roventa-Framusani, 1984).

Aunque la persuasión opera en un terreno más vasto (por ejemplo mediante seducción objetual y personal), la argumentación es uno de sus constituyentes esenciales.

Así, la argumentación como procedimiento para el cambio de estado (cognitivo o físico), es otro tipo de acto-de-habla que, aún sin identificación del agente que argumenta, puede ser comprendido por el niño desde muy temprano. Ello por virtud de otro formato interactivo con el adulto que se manifiesta casi al mismo tiempo que el infante es capaz de comprender la referencia.

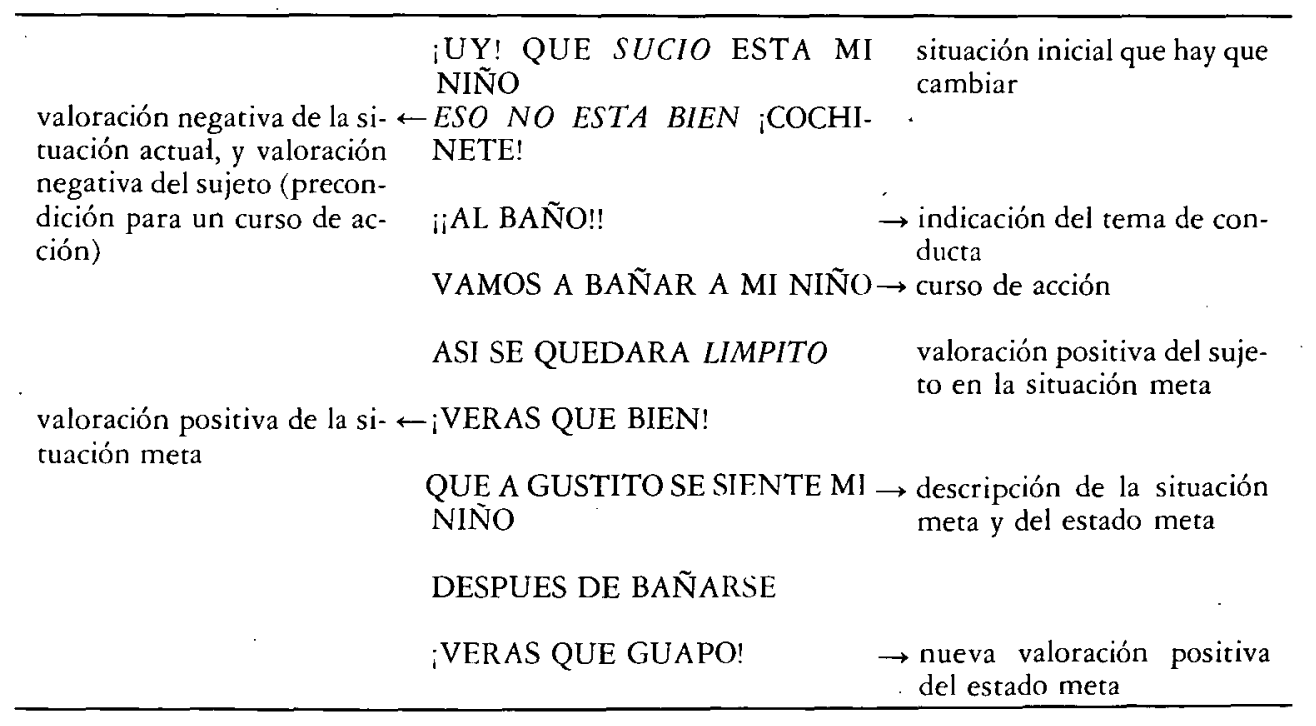

Figura 3. Ejemplo de posible formato de argumentación.

Para el formato proto-argumentativo se crea entre los actores madreniño, o adulto-niño en generàl, un conjunto de precondiciones necesarias y una meta que implica cambio situacional, definiéndose la intención como deseo de cambio de la situación. Así, de estar sucio a estar limpio, y con- 
juntamente un curso de acción, o formato de ejecución, que de la situación «A» permite pasar a la situación «B», en nuestro caso estar limpio. Al tiempo, el adulto verbaliza el curso de acción, correlacionándolo con la meta, que, mediante valoración, se intenta hacer deseable.

La valoración suele formar parte de los recursos argumentativos, y aunque su estatuto como acto-de-habla independiente es contradictorio (Wolf, 1984), podríamos considerarlo otro acto-de-habla que debe conocerse. Aquí, sin embargo, lo incluimos en el más global de la argumentación, considerando los componentes descriptivo y valorativo como inseparables.

Es un ejemplo ficticio, no por ello menos habitual que, con sus diferentes variables superficiales posibles, ejemplifica lo que queremos decir respecto al formato de la argumentación que el niño, desde pequeño, conoce.

En esencia podría resumirse como sigue:

1) constatación descriptiva de la situación $A$.

2) valoración negativa de esa situación $A$.

3) precondiciones que justifican un curso de acción cuya intención es cambiar la situación A.

4) descripción del curso de acción o procedimiento para cambiar la situación.

5) descripción de la situación meta B, o situación deseable.

6) valoración positiva de la situación $B$.

7) valoración del sujeto en la situación $B$.

Este formato, como otros, se repite siempre igual, aunque puede variar su manifestación superficial, y es aprendido por el niño como los demás.

Vemos en él los elementos esenciales que también la publicidad utiliza de forma elemental, diríamos que respetando el formato comprensible por el niño.

El enfrentamiento situacional (antes y después del uso del producto) es un recurso habitual en publicidad, y a veces con una utilización muy primaria, que el niño perfectamente puede comprender.

Pero frente a las formas de predicación infantil, lo que la publicidad hace es utilizar estos recursos para adscribir la predicación no al objeto, sino a la marca, aunque el mecanismo que utilice para ello sea el mismo que el de la predicación de los objetos en los niños. Utiliza los mismos formatos. Con ello vacía el objeto de significado y llena de significado a la marca, utilizando luego el mecanismo inverso, esto es, llamar con el significado de I marca cualquier objeto fabricable.

En este sentido, en publicidad, el significado no está en los objetos, sino en los procedimientos de significar a cualquier cosa o entidad abstracta (González Martín, 1982).

\section{LA COMPRENSION PLENA DE LA PUBLICIDAD}

Hasta aquí, he tratado de mostrar cómo el conocimiento de ciertas partes constitutivas del mensaje contribuye a la comprensión, pero también la limitan en la propia finitud de las relaciones de este conocimiento con otros.

Si bien la referencia ostensiva de la publicidad es comprensible casi para cualquier niño desde muy temprana edad y la predicación valorativa también, hay otras partes del discurso que quedan inicialmente incomprendidas hasta que dichos actos-de-habla no se ubican en su nivel superior y el niño es capaz de pasar de un procesamiento guiado eminentemente por 
los datos, a un procesamiento guiado conceptualmente (Kintsch y van Dijk, 1983).

En este sentido, las dificultades del niño para comprender la intención del discurso en su globalidad se relacionan con la constatación de dificultad de descentración, de adoptar el punto de vista de otro, con lo que obtendría una interpretación de la finalidad del discurso.

Esto no es solamente debido al supuesto egocentrismo de las tesis piagetianas (Ward y Wackman, 1973), sino a la cantidad de conocimiento social interactivo de que el sujeto dispone en una edad determinada.

Tengamos en cuenta que mediante los formatos el niño no sólo aprende las pautas de interacción, sino direcciones de dicha interacción. Es decir, el formato lé asigna un papel para el cual le dota de conductas ejecutivas. En los primeros formatos el niño siempre es paciente, sólo más tarde y con un uso prolongado del formato, el niño es capaz de lograr una reversibilidad de la interacción, pudiendo entonces él mismo demandar o iniciar el formato interactivo.

El comprender plenamente un texto o discurso implica tener esa capacidad de reversibilidad, de poder adoptar mentalmente la posición del otro (emisor) previendo así su meta y, como consecuencia de ella su plan ejecutivo.

El conocimiento social necesario es entonces enorme, sobre todo para la comprensión del desempeño del rol en un sujeto emisor, saber que según el rol (padre, abogado, amigo, miembro de un club, aficionado al ski, etc.) así variarán sus metas y sus planes para alcanzarlas.

El niño, en general, ve a las personas según un único papel cuando comienza su interacción mediante formatos, le cuesta entender la asunción de roles por sí mismo y por otros. Así, le resulta difícil saber a qué se refiere la gente cuando habla desde el desempeño de un rol, con sus reglas regulativas diferenciales (Searle, 1969) que él aún no ha manejado en ningún formato de los iniciales.

Si el niño desconoce, pues, a los actuantes de la comunicación, difícilmente podrá, mediante descentramiento, adoptar para la comprensión el punto de vista de los personajes intervinientes. Y la argumentación publicitaria, como cualquier otra, difiere en función del punto de vista. Al adoptar un papel cambian los principios que se utilizan como norma compartida, en la legitimidad de la opción elegida, según el cuadro de la figura 2.

El niño se integra en el consumo, sin embargo, en gran parte a través de la publicidad. Pero se integra en él como en los juegos, esto es, como paciente. Son los demás los que inicialmente juegan con él, los que imponen las reglas a las que él se atiene; es incapaz, hasta cierta edad, de trascender estas reglas y crear unas nuevas donde sea él el agente y el otro el paciente. Así va asumiendo las reglas de integración en grupos, creando su propia identidad por descubrimiento de sus pertenencias y carencias (por ejemplo, «no puedo jugar con los otros niños porque no tengo un Scalextric»). Va consumiendo los significados que la sociedad, a través de la publicidad le ofrece, alejándose cada vez más de los significados propios, o de los que uno mismo puede construir para las cosas.

Tal vez de mayor pase a ser otro de los que construyen esos significados para los demás, pero quizá lo haga como un acto más de consumo, siendo de nuevo paciente de una estructura laboral en la que le toca desempeñar el juego del constructor de significados.

Según esto, el paso definitivo a la comprensión de la publicidad se logra cuando el niño representa en alguna forma al emisor y la intención global del mensaje. 
La comprensión se facilita si se atiende solamente a la intención global del texto y se desestiman los detalles (de Beaugrande, 1984).

Así, el recorrido comprensivo del niño podría ser como sigue:

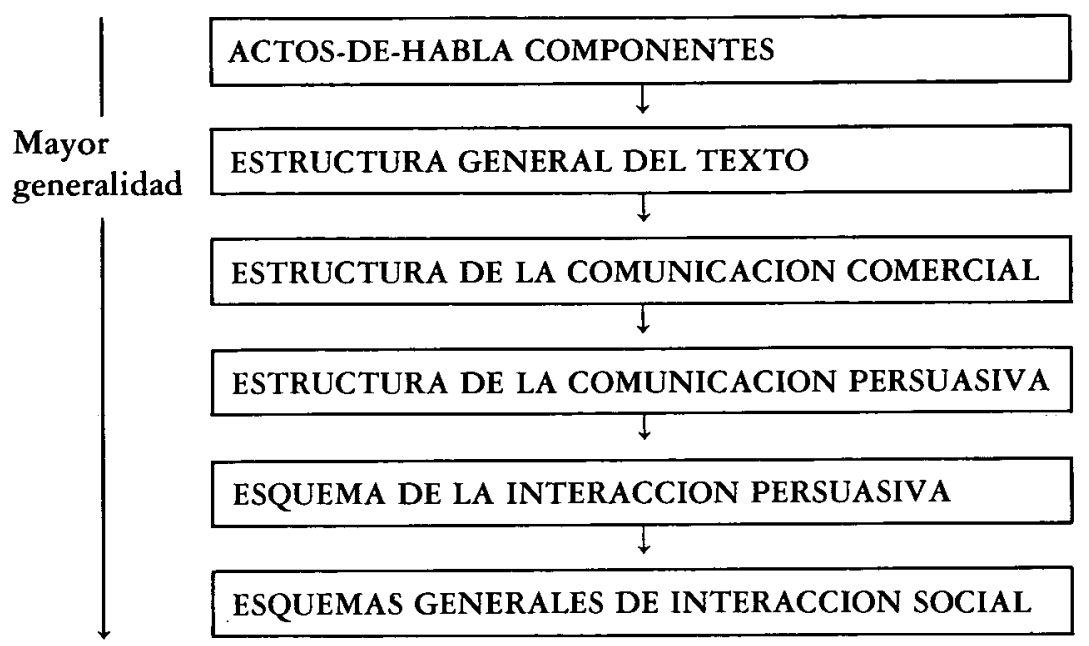

A medida que pasamos a una mayor generalidad va siendo más claro el proceso al ir integrando los elementos del caso (en el sentido de Filmore, 1968): actantes, evento, situación, etc., y poder determinar en el esquema el papel del sujeto que recibe el texto y la intención de influencia del emisor de la comunicación para algún otro fin o meta general.

En este sentido el aprendizaje explícito de la superestructura esquemática del mensaje (fig. 2) puede ser un paso intermedio que ayude metacognitivamente al niño, al permitirle integrar su comprensión de las partes en un todo único que funciona conjuntamente para el logro de una meta. Este aprendizaje permitirá la utilización de la superestructura como esquema canónico que conlleva la posibilidad de comparación de los ejemplares defectivos (menos típicos, en la terminología de Rosch, 1978), de la categoría, ayudando a ver que incluso ante la ausencia de la argumentación, esta categoría funciona de forma elidida, con la intención de convencer al receptor en una dirección determinada.

El esquema es así operativo en el sentido Rumelhart y Ortony, (1977), como núcleo de elementos predecibles que permite la comprensión de lo faltante y la expectación de lo subsiguiente. Es a lo que se refiere Greenfield, (1984), en una perspectiva similar a la aqui adoptada, respecto a una amplia lectura del discurso televisivo.

\section{EL PAPEL DE LA SOBRESIGNIFICACION}

Una comprensión del mensaje publicitario en el sentido propuesto ayudaría, sin duda, al niño a defenderse de la persuasión publicitaria. Pero hay mecanismos de la publicidad televisiva y del discurso televisivo en general, que inician ciclos de persuasión que escapan a la pura argumentación racional. Sin entrar en las vías argumentativas retóricas del «ethos», «pathos», y «logos» (donde el «logos» se abandona publicitariamente en favor del «ethos» y del «pathos» aristotélicos), cuenta la publicidad televisiva con un aliado persuasivo como son las tecnologías. 
Los recursos técnicos que utiliza la telèvisión permiten múltiples manipulaciones (retóricas) visuales del objeto y de la realidad en general.

Por virtud de las tecnologías, el objeto se sobresignifica, generalmente mediante hiperatribución (tamaño, color, deformaciones, dinamismo de objetos estáticos, etc.), que modifican la relación del objeto con el resto de elementos que integran las representaciones canónicas de los mismos.

Esta. sobresignificación conlleva, por su propia esencia, un incremento de la valoración, que modifica la tríada atributo-valor-emoción, en el sentido de Tajfel (Tajfel, 1981), produciendo así una carga afectiva de adhesión superior a la habitual para el objeto normalmente significado, que se manifiesta en mayor deseabilidad del mismo.

Esta sobresignificación (Beaudrillard, 1984) es como un algo más añadido al objeto, inicialmente por virtud de las tecnologías, sean estas instrumentales o simplemente discursivas (como la retórica), pero que han sabido autonomizar del propio objeto los marketinianos y publicitarios. Es decir, pasar de esa sobresignificación inicial a un subsiguiente cambio del significado, con todas las repercusiones que ello conlleva para el consumo simbólico. Así, en el niño se inicia un ciclo que permite pasar de esta sobresignificación puramente tecnológica a una subsiguiente modificación del significado del producto, e incluso a la creación para el mismo de un significado artificial que, finalmente, es lo que se consume de forma simbólica (González Martín y Benavides Delgado en este número).

\section{CONCLUSIONES}

La intención del artículo ha sido mostrar cómo el mensaje publicitario es tratable, en algún sentido, desde un desglose pormenorizado de su estructura, que facilite la comprensión del niño.

La consideración del mensaje publicitario como acto-de-habla global, nos ha permitido considerar una organización de actos constituyentes que, cumpliendo una función parcial en el discurso completo, están al alcance comprensivo del niño, que los conoce como formatos interactivos. Pero, pese a esa comprensión parcial, el comprender el mensaje publicitario implica la integración de sus coṇstituyentes en un todo, que actúa como conducta global de un agente.

Es pues el conocimiento y representación del agente emisor y de su meta pragmática lo que supone un paso cualitativo importante en la comprensión del mensaje, pero que sin embargo esto no evita la actuación de ciertos mecanismos persuasivos que, ligados a las tecnologías, la publicidad utiliza con gran efectividad.

Sin duda, la atención que se preste en esta línea a la comprensión de la comunicación comercial más amplia, entre la que se incluye la publicidad, puede ayudar a la elaboración de un modelo holista e integrado del consumo, que en última instancia es la meta que anima la mayor parte de los artículos de este Tema Monográfico.

\section{Notas}


El propósito central de este articulo es mostrar cómo un modelo iniegrado, multidisciplinar, puede dar cuenta de la comprensión del mensaje publicitario por el niño. El modelo parte de la consideración del mensaje como acto-de-babla-global y su representación cognitiva por el receptor, como esquema de acción e interacción. Este doble abordamiento permite trascender el marco de las teorias de la competencia, hasta abora dominantes, y explicar, en cierto modo, la actuación concreta de los sujetos en la comprensión de los mensajes.

\section{Summary}

This paper's main purpose is to show bow an integrated, multidisciplinary model can report the children's comprebension of the advertising message. The model reckons from the consideration of the message as a global-speech-act and its cognitive representation from the receiver, as an action an interaction's schema. This double approach permits to surpass the competence theories framework, which prevail until present, and explain, in a certain way, the specific performance of individuals in the messages comprebension.

\section{Résumé}

Le but central de cet article est celui de montrer comment un modèle intégré, multidisciplinaire, peut donner compte de la comprébension du message publicitaire par l'enfant. Le modèle part de la considération du message en tant qu'un acte-de-parole-globale et sa représentation cognitive de la part du récepteur, en tant que schéma d'action et interaction. Cette double approche permet de surpasser le domaine des théories de la competence, dominantes jusqu'à present, et d'expliquer, dans un certain sens, la performance concret des sujets dans la comprébension des messages.

\section{Referencias}

Austin, J. L.: How to do things with words. Oxford: Ed. Oxford University Press, 1963 (trad. esp., 1971. Paidós). BeAUdRILlaRD, J:: De la seducción. Madrid: Cátedra, 1984.

Beaugrande, R. de: Text production. Norwood, N. J.: Ed. Ablex, 1984.

BERNÁRDEZ, E.: Introducción a la lingüística del texto. Madrid: Espasa-Calpe, 1982.

BRUNER, J. «De la comunicación al lenguaje: una perspectiva psicológica», en Monografías de Infancia y Aprendizaje, 1981, 133-165.

BRUNER, J.: Child's talk. Learning to use language. Londres: W. W. Norton, 1983 (trad. esp. Paidós, 1986).

Bruner, J.: Acción, pensamiento y lenguaje, (compilación de José Luis Linaza). Madrid: Alianza, 1984.

CARrera, F.: «Ethos-Pathos-Logos: formulación original aristotélica, distorsiones interpretativas y vigencia en comunicación persuasiva de masas», en Cuadernos de Realidades Sociales, 1980, 16-17, pp. 19-56.

CARRERA, F.: Vigencia de los modelos aristotélicos en teoria e investigación de la comunicación persuasiva de masas. Tesis Doctoral en Filosofía. Universidad Complurense de Madrid, 1978.

CONNOR, U., y LAUER, J.: «Understanding persuasive essay writing: linguistic/rethorical approach», en Text, $1985,5,(4), 309-326$.

FILMORE, C.: «The case for case», en E. Back y R. I. Harms (eds.: Universals in linguistic Theory), Nueva York: Holt, Rinehart and Winston, 1968.

Garcia Berrio, A. y Albadalejo Mayordomo, T.: «Estructura composicional. Macroestructuras», en Estudios de Lingüística. Universidad de Alicante, 1983, 1, 127-179.

Gonzalez Martin, J. A.: Fundamentos para la teoria del mensaje publicitario, Madrid: Forja, 1982.

GREENFIELD, P. M.: El niño y los medios de comunicación, Madrid: Morata, 1985.

Grice, H. P.: «Logic and conversation», en P. Cole y J. L. Moorgan (eds.): Syntax and Semantics, vol. 3, Speech Acts. Londres y Nueva York, Academic Press, 1975.

Halliday, M. A. K.: Language as social semiotic. The social interpretation of language and meaning. Londres: Edward Arnold, 1978.Trad. esp. F.C.E., 1982.

Hernadi, P.: Teoría de los géneros literarios. Barcelona: Antoni Bosch, 1978.

KINTSCH, W: Memory and cognition, Nueva York: Willey, 1977.

KINTSCH, W., y VAN DIjK, T.A.: Strategies of discourse comprebension, Nueva York: Academic Press, 1983.

KOPPERSCHMIDT, J.: "An analysis of argumentation», en T. A. van Dijk (Ed.): Handbook of discourse analysis. Londres: Academic Press, 159-168.

Lavandera, B.R.: Curso de lingüistica para el análisis del discurso. Buenos Aires: Centro Editor de América Latina, 1985.

Marchesi, A., y Paniagua, G.: «El recuerdo de cuentos e historias en los niños», en Infancia y aprendizaje, $1983,22,27-45$. 
Panigua, G y Marchesl, A.: «El recuerdo de cuentos», en Cuadernos de Pedagogía, 1985, 130, $21-23$.

Peninou, G.: Intelligence de la publicite. Etude semiotique. París: Robert Lafont (trad. esp., Gustavo Gili, 1976).

Perelman, Ch.: Le Champ de l'argumentation. Bruxelles: Presses Universitaires de Bruxelles, 1970.

PIERCE, C. S.: Collected Papers. Cambridge, Massachusetts: Harvard University Press (parcialmente traducido en La Ciencia de la Semiótica. Buenos Aires: Nueva Visión, 1984).

PIKE, K. L.: Language in relation to a unified theory of the structure of buman bebavior. La Haya: Mouton, 1967 (2. ${ }^{\text {a }}$ edición).

Putnam, H.: Mind, language and reality. Cambridge: Cambridge University Press, 1975.

RANDQUIST, M.: "The TT-schemata as a necesari prerequisite of skilled writing", Text, 1985, 5(4), 371-385.

Rosh, E.: «Principles of categorization», en Roch y Lloyd (eds.): Cognition and categorization. Hillsdale, N. J.: L.E.A., 1978.

Roventa-Framusani, D.: «Argumentation neo-rhétorique et théorique de l'action», en Revue roumaine de lin. guistique XXIX, 3, 247-256.

RumelhaRT, D.: «Notes on a schema for stories», en Bobrw y Collins (comps.): Representation and unders. tanding, Nueva York: Academic Press, 1975, 211-236.

Rumelhart, D., y Orotony, A.: "The representation of knowledge in memory", en A. C. Anderson, R. J. Spiro y W. E. Montague (eds.): Schooling and the aequisition of knowledge. Hillsdale, N. J., Erlbaum, 1977, 99-135 (Trad. esp., Infancia y Aprendizaje, 19-20).

Sं̈HANK, R. C. y ABELSON, R. P.: Scrips, plans, goals and understanding. Hillsdale, N. J.: Erlbaum, 1977.

SCHANK, R. C.: «El papel de la memoria en el procesamiento del lenguaje», en Ch. N. Cofer (ed.): Estructura de la memoria humana, Barcelona: Omega, 1979.

Schank, R. C.: Dinamic Memory. Cambridge: Cambridge University Press, 1982.

SCHMitd, S. J.: Texttbeorie, Munich: Wilhelm Fink Verlang, 1973 (trad. esp., Cátedra, 1978).

SEARLE, J.: Speech acts: an essay in the Philosophy of Language. Londres: Cambridge University Press, 1969 (trad. esp., Cátedra, 1980).

SEARle, J.: "What is a speech act?», Pbilosopby in America. Londres: Allen and Unwin, 1965 (trad. esp., Teorema, 1977).

Stein, N. L. y GlenN, L. G.: «An analysis of story comprehension in elementary school children», en R. V. Freedle (ed.): New Directions in discourse processing. Norwood, N. J.: Ablex, 1977.

TAJFEL, H.: Human Groups and social categories, Cambridge: Cambridge University Press, 1981 (trad. esp., Herder, 1984).

THORNDYKE, P. W.: «Cognitive structures in comprehension and memory of narrative discourse», Cognitive psichology, 1977, 9, 7/110

VAN DIJK, T.A.: Text and context: exploration in the semantics and pragmatics of discourse, Londres: Longman, 1977 (trad. esp., Cátedra, 1980).

VAN DIjK, T. A.: Tekstwetenschap. Een interdisciplinaire inleiding. Utrecht: Het Spectrum, 1978 (trad. esp., Paidós, 1983).

VAN DiJK, T. A.: Macroestructures. And interdisciplinary study of global structures in discourse, cognitions and interaction, Hillsdale, N. J., Erlbaum, 1980.

WARD, S. y WACKMAN, D. B.: "Children information processing of television dovertising», P. I. Larke: New models for mass communication research,. Londres: Sage Publications, 1978.

VIDAL, P.: Fundamentos para una teoría general de la creatividad publicitaria, 1986 (en preparación).

WOLF, E M., «El significado valorativo de los actos del discurso», Quaderni di Semantica, 1984, 1/89 (original en castellano). 